\title{
Challenges of solving the problem of soil and groundwater contamination
}

\author{
-An interdisciplinary approach-
}

\author{
Ming ZHANG \\ [Translation from Synthesiology, Vol.12, No.1, p.39-47 (2019)]
}

\begin{abstract}
Feasible countermeasures are needed to address soil and groundwater contamination problems, because of its impact on human health and socioeconomic activities. Soil and groundwater contamination is a complex issue that requires an interdisciplinary effort involving research into contaminants, their practical removal, and social implementation. This paper discusses several areas of research that the author has been involved in this regard.
\end{abstract}

Keywords : Soil and groundwater contamination, remediation technologies, environmental regulation, sustainable development

\section{Introduction}

Soil and groundwater contamination is an "old and new environmental problem." In the past, there was the "Ashio Copper Mine Pollution" incidence, and recently, there are the radioactive contamination induced by the Fukushima Daiichi Nuclear Power Plant accident and the soil contamination at the Toyosu Market site. Soil and groundwater contamination can be called a "negative legacy" of various industrial activities, and it changes according to periods and industrial structures. Moreover, regulations also change according to policies and cultural evolution.

In Japan, mining and refining industries developed rapidly with the growth of heavy industries in the latter half of the 19th century, and pollution of agricultural land by mine drainage became serious social issues. The incident in which agricultural land along the Watarase River was polluted in the late 1880s (known as Ashio Copper Mine Pollution) became the origin of pollution issues in Japan. Beginning with the itai-itai disease (cadmium poisoning) that occurred in the Jintsu River basin of Toyama prefecture in 1968, the "Act to Prevent Soil Contamination on Agricultural Land" went into effect in 1970. According to the report ${ }^{[1]}$ published by the Environmental Management Bureau, Ministry of the Environment in December 2016, the surface area of land, from which hazardous material surpassing the environmental standard set by the law was detected, was 7,592 ha as of the end of FY 2015, and the countermeasures were completed for about $92.7 \%$ of the contaminated land. As it can be seen, even after conducting countermeasures for over 50 years after the discovery of soil contamination in agricultural land, the measures have still not reached $100 \%$. There were only three contaminants designated in the "Act to Prevent Soil Contamination on Agricultural Land," and cadmium is regulated because of health effect to humans, while copper and arsenic are regulated because they cause growth disruption in plants. In December 2014, the standard value for cadmium in Japanese rice was revised from $1.0 \mathrm{mg} / \mathrm{kg}$ to $0.4 \mathrm{mg} / \mathrm{kg}$ that is the WHO standard. As the standard was raised, there is concern that issues would become apparent in certain regions in the future.

After WWII, pollution by volatile organic compounds (VOC) and heavy metals such as lead and hexavalent chromium became apparent accompanying the development of chemical and manufacturing industries. In the report published by the Geo-environmental Protection Center in 2000 , there are about 930 thousand industrial businesses that have the possibility of causing pollution, the investigation cost will be about 2 trillion yen, and the decontamination cost is estimated to be about 11 trillion yen. ${ }^{[2]}$ In Japan, the laws pertaining to soil contamination in the urban area is lagging 20 years behind the American Comprehensive Environmental Response, Compensation, and Liability Act (also known as Super Fund Law, established in 1980), but the "Soil Contamination Countermeasures Act" (hereinafter, Countermeasures Act) was established in 2003. In this law, the contaminants are categorized into category 1, 2, and 3 designated hazardous substances, and these refer to VOCs, heavy metals, ${ }^{\text {Term } 1}$ and agrichemicals and PCB, respectively. After undergoing several amendments, as of now, there are 12,9 , and 5 substances that are designated as category 1 , type 2, and type 3 designated hazardous substances (total

Research Institute for Geo-Resources and Environment, GSJ, AIST Tsukuba Central 7, 1-1-1 Higashi, Tsukuba 305-8567, Japan E-mail: m.zhang@aist.go.jp

Original manuscript received January 6, 2019, Revisions received January 22, 2019, Accepted January 24, 2019 
26 substances) under the Countermeasures Act. Note that the designated hazardous substances consist of only a very small portion of about 65,000 chemical substances that are used in Japan. Also note that the current environmental regulations of Japan are not based on risks but are uniform environmental standard values.

With the enforcement of the Countermeasures Act, cases of investigation and countermeasures for soil contamination have increased every year in Japan. According to the latest report published by the Environmental Management Bureau, Ministry of the Environment, there are about 1200 cases of investigation and countermeasures based on the regulations, and there may be several thousand more cases if the voluntary measures by private companies are included.$^{[3]}$ However, there are potentially hundreds of thousands of contaminated sites, and several thousand cases is only $1 \%$. It is quite clear that a long road lies in front of us in solving the problems of soil and groundwater contamination.

In this paper, we present the diversity and complexity of soil and groundwater contamination problems, describe the elemental technologies needed to rationally solve the problems of soil and groundwater contamination, construct and discuss the scenario for implementation in society, and introduce some research cases in which the author was involved.

\section{Diversity and complexity of soil and groundwater contamination}

There are three categories and 26 substances that are designated as hazardous substances (contaminants) in the Countermeasures Act, but there are numerous other toxic and/or harzarous substances that may actually affect human health. In Europe, the contaminants are categorized into heavy metals, aromatic hydrocarbons (BTEX = benzene, toluene, ethylbenzene, trimethylbenzenes and the three xylene isomers), organochlorine compounds $(\mathrm{CHC}=$ chlorinated hydrocarbons), polycyclic aromatic hydrocarbon (PAH), and mineral oils. ${ }^{[4]}$ In Japan, although the "Oil Contamination Countermeasure Guideline" was published, there is no regulation by law. ${ }^{[5]}$ There are several isomers of BTEX, CHC, and PAH, but the VOCs designated in the Countermeasures Act includes only some of BTEX and CHC.

The Fukushima Daiichi Nuclear Power Plant accident was induced by the Great East Japan Earthquake and Tsunami of March 11, 2011, and contamination by radioactive substances occurred over a wide area. To take measures against this urgent issue, the "Act on Special Measures Concerning the Handling of Environment Pollution by Radioactive Materials Discharged by the Nuclear Power Station Accident Associated with the Tohoku District-Off the Pacific Ocean Earthquake That Occurred on March 11, 2011" was adopted in August 30, 2011 and went into effect on January 1, 2012. That is, the contamination by radioactive materials is out of the range of the Countermeasures Act.

The revised "Industrial Safety and Health Act" was implemented on June 1, 2016, and the risk assessment of chemical substances became an obligation. In this revision, the businesses, which manufacture or handle 640 target chemical substances for which certain levels of danger and hazards have been confirmed, are obligated to conduct risk assessment, regardless of the business type or size. Also, for the water standard based on the Waterworks Law, other than the 51 regulated items, 26 items for which water management goals are set and 47 items that should be investigated (total 124 items) are designated. As it can be seen, there are only a few chemical substances regulated by the Countermeasures Act. This is because the soil contamination problem is extremely complex, the investigation and countermeasures are not easy, and realistically it is difficult to enforce strict regulations. ${ }^{[6]}$ At this point, there are possibilities that the substances that are not currently regulated by the Countermeasures Act may become regulated in the future, and in some cases, they may become social issues. In fact, chloroethylene (vinyl chloride) was added to the list of regulated substances under the Countermeasures Act in April 2017, and land that was not contaminated turned into contaminated land according to the laws, and there were cases in which land became unsellable or non-developable.

In addition to the diversity of the contaminants, the diversity, heterogeneity, and anisotropy of soils, as well as strong adsorption between organic substances and clay minerals make the soil contamination problem extremely complex. Also, for some contaminants, pollution may occur in chain reaction due to material circulation in nature (Fig. 1). In the Basic Environment Law, soil contamination is positioned as one of the "seven major types of pollution" including air pollution, water pollution, noise, vibration, ground

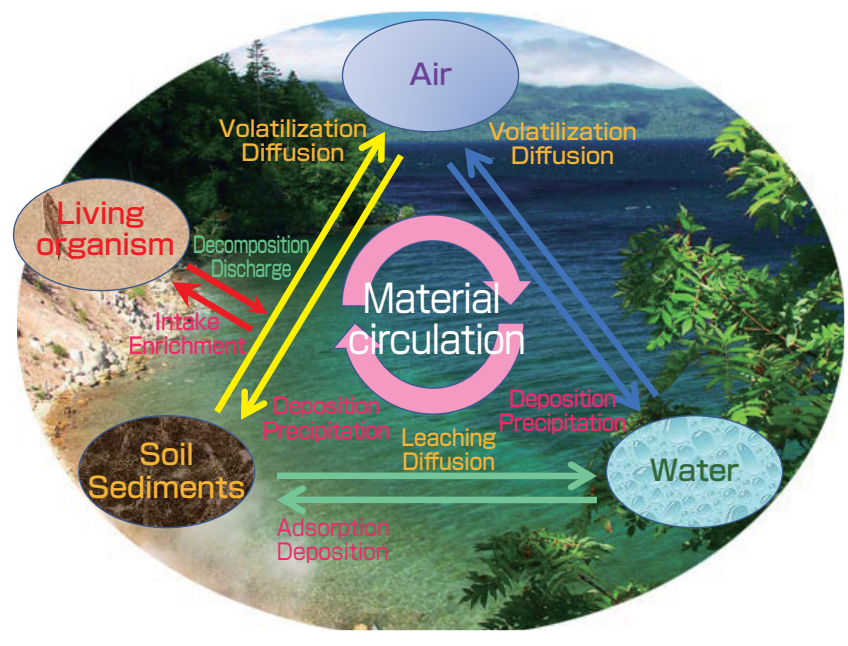

Fig. 1 Interactions among air, water and soil pollutions due to material circulation 
subsidence, and bad odor.

These kinds of pollution may not occur alone but may occur simultaneously depending on the cause. For example, odorous volatile chemical substances may cause bad odor, as well as simultaneously cause air pollution, water pollution due to rain, and soil and groundwater contamination by percolation. As it can be seen, to conduct investigation and countermeasures for soil and groundwater contamination problems, it is absolutely essential to integrate knowledge and technology from various fields.

\section{Synthesiological significance of research pertaining to soil and groundwater contamination}

The synthesiological significance of risk assessment technology and self-management methods for soil and groundwater contamination have been discussed by Komai et al., ${ }^{[7]}$ but to solve the problems of soil and groundwater contamination that are becoming more diverse and complex, risk assessment and self-management technologies, though mandatory, are not sufficient. To rationally and efficiently solve the diverse and complex soil and groundwater contamination problems, it is necessary to systematically develop technologies for appropriately investigating and assessing the type and form of contaminants, remediation and countermeasure technologies of low cost and low environmental load, and technologies for risk communication based on risk assessments. Moreover, it is necessary to transfer science and technology research to society through engineering methods. In the application to actual issues, it is necessary to also consider not only environmental aspects but also economic and social aspects. In the decision-making process for the selection of remediation methods, elemental technologies should be incorporated as part of the scientific evidence for decision making, and flexibly integrated. This is the rational countermeasures for soil and groundwater contamination considering sustainable development, and it is also called sustainable remediation. ${ }^{[8]-[10]}$

Figure 2 shows the scenario of feasible remediation for soil and groundwater contamination considering sustainable development. In the social implementation of the technology, involvement of all stakeholders including local residents is important, besides collaboration among industry, academia, and government, and this is one of the issues that must be advanced in Japan. One of the reasons there was social confusion about the soil contamination problem at the Toyosu Market site was because of the absence of stakeholders' involvement.

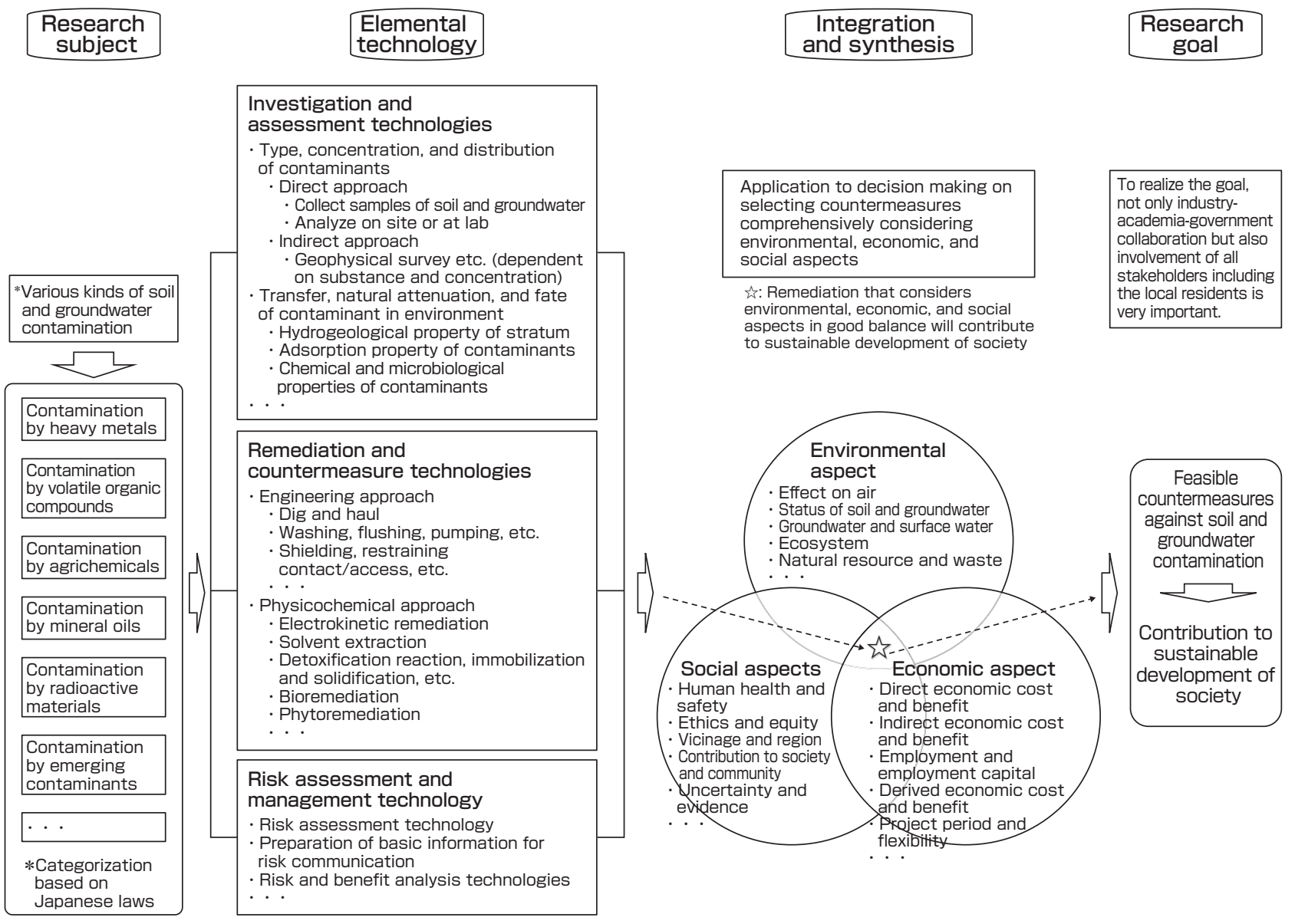

Fig. 2 Scenario for feasible remediation of soil and groundwater contamination considering sustainable development 
Table 1. Major fields of specialty for soil and groundwater contamination R\&D

\begin{tabular}{|c|c|}
\hline $\begin{array}{l}\text { Elemental technology } \\
\text { category }\end{array}$ & Objective and related fields of specialty \\
\hline \multirow{2}{*}{$\begin{array}{l}\text { Investigation and } \\
\text { assessment } \\
\text { technologies }\end{array}$} & Objective: To understand the problem and to grasp the current status \\
\hline & $\begin{array}{l}\text { - Investigation: Chemistry, soil chemistry, organic chemistry, microbiology, } \\
\text { instrumental analysis, geophysical survey } \cdots \\
\text { - Assessment: Hydrogeology, mathematical science } \cdots\end{array}$ \\
\hline \multirow[b]{2}{*}{$\begin{array}{l}\text { Remediation and } \\
\text { countermeasure } \\
\text { technologies }\end{array}$} & Objective: How to reduce the human health risks due to contamination \\
\hline & $\begin{array}{l}\text { - Remediation and measures: Chemical engineering, electrochemistry, geochemistry, } \\
\text { environmental microbiology, environmental engineering... } \\
\text { - Management: Civil engineering, hydrogeology, environmental economics, } \\
\text { social economics } \cdots\end{array}$ \\
\hline \multirow{2}{*}{$\begin{array}{l}\text { Risk assessment } \\
\text { and management } \\
\text { technologies }\end{array}$} & Objective: Smooth implementation of scientifically based risk communication \\
\hline & $\begin{array}{l}\text { - Risk assessment: Soil physics, mathematical science, toxicology, ecology } \cdots \\
\text { - Risk communication: Social psychology, political philosophy, ethics } \cdots\end{array}$ \\
\hline
\end{tabular}

There are multiple approaches and research topics for the investigation and assessment technologies of soil and groundwater contamination, the remediation and countermeasure technologies, and the risk assessment and management technologies. Figure 2 shows only the representative items. To develop these technologies, knowledge spanning over several fields are absolutely essential, and Table 1 shows the objectives of the development of various technologies and their main fields of specialty. As it can be seen, the research on soil and groundwater contamination is an interdisciplinary research that covers science, engineering, and social economics. It is a complex social problem that cannot be solved by a single field.

\section{Strategic technological development for treating with soil and groundwater contamination}

Although technological development is being done on investigation and countermeasures for soil and groundwater contamination, there are still misunderstanding about the findings and limitation of application to real problems. Although investigation and countermeasures based on the current Countermeasures Act has strong binding power, it is not necessarily scientific or rational. For example, in a certain area with possibility of contamination, the sample collection in a planar direction is uniformly $10 \mathrm{~m}$, and the measures are for a basic unit section of $100 \mathrm{~m}^{2}$ that are divided in lattice of $10 \mathrm{~m}$ intervals. In a case of actual contamination by heavy metals such as lead, due to the adsorptivity of soil, the contamination is likely to be in a narrower range than $10 \mathrm{~m}$, and conducting measures in a $100 \mathrm{~m}^{2}$ unit is not economical. Also, since the current Countermeasures Act is conducted under uniform environmental standard values, there are cases that are designated as contaminated even though human health risks are not that great, and there are cases which are considered not contaminated or having completed decontamination as long as the analysis by a designated investigation organization ${ }^{\text {Term } 2}$ shows values less than the environmental standard. In fact, although it may depend on the contaminant, soil type, or geological conditions of the site, there may be some cases in which the values may be above the environmental standard if analyzed by a different designated investigation organization. This is because the precision shifts depending on the method and subject of analysis, as well as the experience of person conducting the analysis. ${ }^{[1]}$ Considering such a background, the Geo-Environmental Risk Research Group to which the author belongs conducts strategic R\&D looking at the changes in future regulations and provides support for the self-investigation and countermeasures for companies and businesses. Here, some research topics in which the author was involved are introduced.

\subsection{Technological development for investigation and assessment}

Soil is a medium with a complex system and the analysis results of contaminated soil is dependent on places of sample collection, collection methods, pretreatment, analysis methods, analysis devices, and others. ${ }^{[12]}$ The analysis based on the Countermeasures Act is called the "official analysis method," and assessment is done only by the analysis result, ${ }^{[1][13]}$ and there is no investigation of mechanisms that may be informative, such as the existence form of contaminants or selection of remediation and countermeasure technologies. For example, heavy metals have standards for "total concentration" and "leaching concentration." In the total concentration test, the $0.1 \mathrm{~mol} / \mathrm{L}$ hydrochloric acid extraction method is used. In this test method, the assessment of "true total concentration" cannot be done, but even the specialists often misunderstand and think that the figure is the "total content." If an inappropriate countermeasure is selected based on this misunderstanding, it may lead to failure. Particularly, in a case of naturally occurring contaminated soil, in general, there is a characteristic that the total concentration based on the official method is low while the leaching concentration is high. If one attempts to remediate or cleanup this type of contaminated soil, there is 
a possibility that the value will not become lower than the environmental standard even after repeated washing. This is because the true total concentration is much higher than the analysis value obtained by the official analysis method.

To solve such a problem, the author and research collaborators are developing an assessment method looking at the existence form of contaminants. For example for a lead-contaminated soil that exists frequently due to natural causes, we clarified the existence form of lead-containing minerals using sedimentation classification and X-ray diffraction analysis, and established a simple quantitative analysis method. ${ }^{[14]}$ Samples that were classified by particle diameter were subject to whole rock chemical analysis using a portable X-ray fluorescence (XRF) analyzer (Niton XL 3t-900S-M, Thermo Fisher Scientific Inc.). Mixed samples in which the weight ratios of each sample and the standard sample (metal silicon) were 1:1 were made, each mineral phase was identified, and simple quantitative analysis of the phases was conducted using an X-ray powder diffractometer (Smart Lab, Rigaku Corporation). For the quantitative analysis of the mineral phase in the sample, the integral strength of the diffraction peak of the standard sample was set at 50, and the relative amount of an unknown sample was calculated. When this was used to assess two samples collected at a certain site, one sample showed a positive correlation between lead concentration and particle size, and a good correlation with galena content. In the other sample, there was a negative correlation between lead concentration and particle size, and a positive correlation with alunite content (Fig. 3) ${ }^{[14]}$ In the field of soil contamination, there is a method called particle size classified washing, and it is one of the frequently used cleanup methods. This method is used under the assumption that a contaminant is adsorbed by fine particles which contains many clay substances and have a large specific surface area. However, this assumption is not necessarily valid in the actual contaminated soil. As can be seen, the correlation between particle size of the contaminant and mineral content can be used for deciding which cleanup or countermeasure can be used, as well as the concentration of

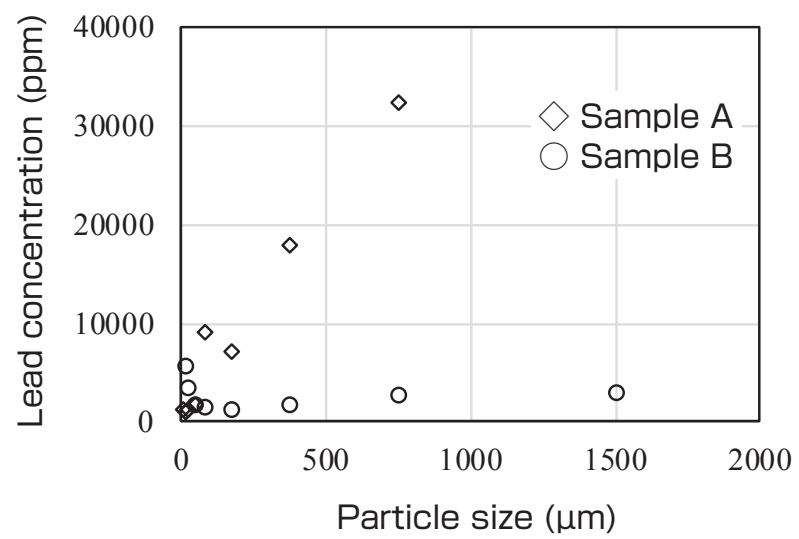

the contaminants.

\subsection{Technological development for remediation and countermeasure}

As technologies for remediation and countermeasure, there are an engineering approach and a physico-chemical approach, and there are several methods in each approach (Fig. 2). However, due to reliability, remediation methods with high cost such as dig and haul were conducted for almost all case studies that were reported. ${ }^{[3]}$ Although 86 billion yen was spent for the remediation of the Toyosu Market site, it has been reported that complete decontamination was not ultimately possible. Therefore, the development of remediation technology of low cost and low environmental load is a research topic with high priority. The Geo-Environmental Risk Research Group is actively working on the remediation technology utilizing mineral materials ${ }^{[15]-[17]}$ and environmental microorganisms. ${ }^{[18]-[20]}$ The former can be used for adsorption and immobilization of heavy metals such as arsenic, and the latter can be used for the decomposition of VOCs. As a point to be added, adsorption is not merely the change in contaminant concentration, but also involves detailed assessment of the environmental stability of spent adsorption material ${ }^{[15]}$ and the soil type and effect of silicic acid in the soil. ${ }^{[16][17]}$ In this research, we conducted systematic evaluation of the main soil types as follows: acidic andosol that is rich in organic components; weak acidic yellow-brown forest soil; neutral Kanuma soil that contains high quantity of allophane (clay made of hydrophilic aluminosilicate with low crystallization and is widely distributed in the volcanic ash zone); alkaline river sand with high silica content; and mountain sand with high iron content. For the decomposition of VOCs using microorganisms, we conducted decomposition tests under conditions replicating combined pollution that occurs at actual contamination sites rather than on a single contaminant. ${ }^{[18][19]}$ Moreover, in decomposition of combined pollution, we identified which microorganism contributed to the decomposition of which contaminant using stable isotope

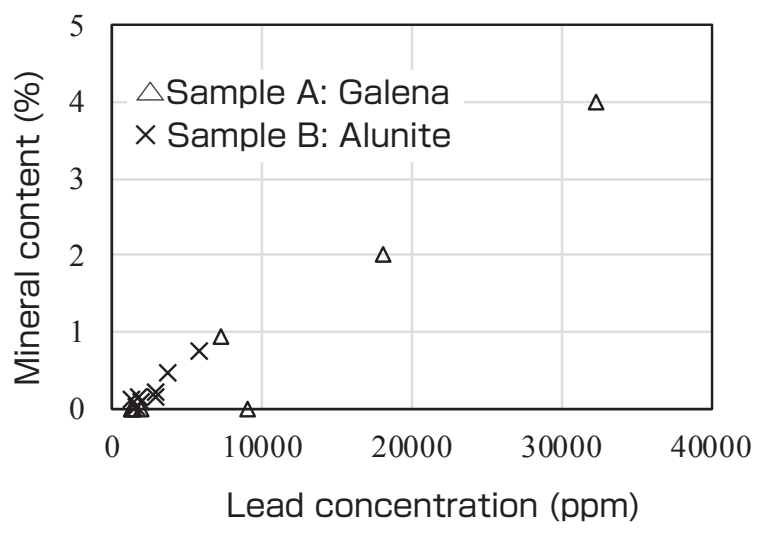

Fig. 3 Relationships among lead concentration, particle size, and mineral content in naturally occurring contaminated soil samples 
probing. ${ }^{[20]} \mathrm{R} \& \mathrm{D}$ is all conducted with practical application in mind.

Figure 4 shows the results of decomposition tests for the 7 kinds of contaminants including tetrachloroethylene (PCE), trichloroethylene (TCE), cis-1,2-dichloroethylene (cis-DCE), chloroethylene (VC), benzene, toluene, and dichloromethane (DCM). The reason for selecting these seven contaminants was because we were able to use the investigation results of an actual illegal dumping site (total amount of waste 1.5 million ton or more, size of $27 \mathrm{ha}$ ). The (a) and (b) in the figure show the results under different testing conditions. (AN)/AE means that the aerobic decomposition test was conducted after anaerobic decomposition, and (AN)/AE-O $\mathrm{O} / \mathrm{AN}$ means anaerobic, aerobic, and then further anaerobic decomposition tests were conducted. The O21 and O5 show the initial oxygen concentration in the headspace of the test bottle in the oxidation decomposition test, and the percentage of volume are $21 \%$ and $5 \%$, respectively. DO is the concentration of dissolved oxygen. It was confirmed that benzene, toluene, and CDM were degraded in the oxidation conditions, and the decomposition of PCE, TCE, cis-DCE, $\mathrm{VC}$, and DCM were confirmed in the reduction conditions, by flexibly applying oxidative decomposition (or aerobic decomposition) by aerobic microorganisms and reductive decomposition (or anaerobic decomposition) by anaerobic microorganisms. The VC was degraded to harmless ethylene, and the complete decomposition of chloroethylenes was confirmed. Also, in this study, it was demonstrated for the first time, that Dehalococcoides that is known as the obligate anaerobic bacteria can survive even if it is exposed to aerobic environment for a certain period and is capable of degrading the chloroethylenes. We were able to obtain extremely useful findings toward designing remediation of combined pollution in the future.

\subsection{Technological development for risk assessment and management}

In order to apply and implement risk assessment and management technologies to society, it is necessary to execute them through risk communication. It is extremely effective to present the degree of risks in an understandable manner, or to indicate the background level of the natural environment that is familiar to us. To contribute to risk communication of heavy metal contamination and to land use planning in the next generation, the Geo-Environmental

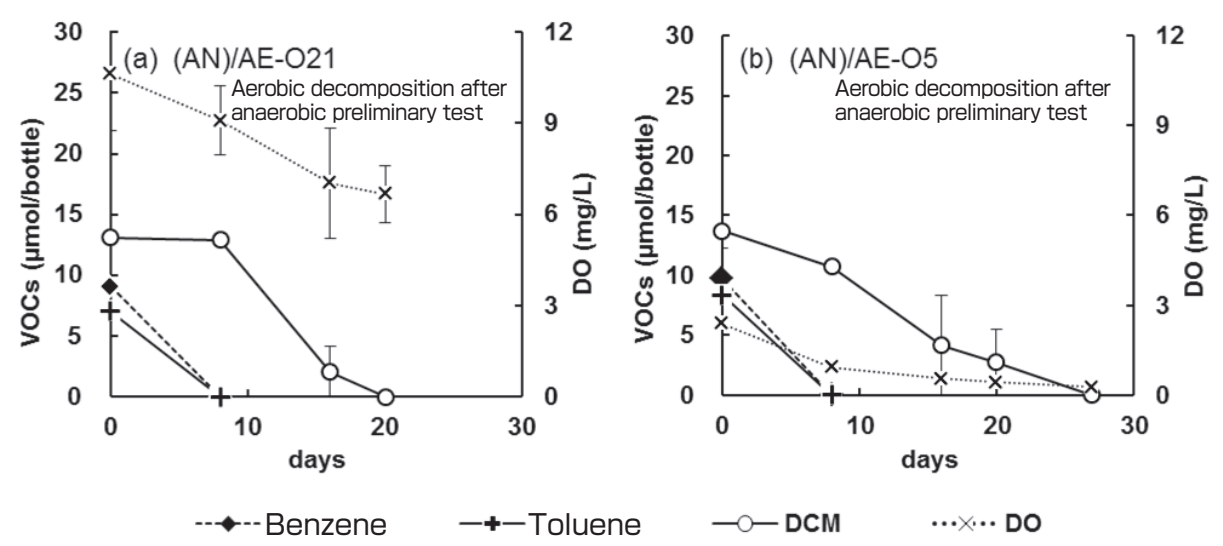

a) Oxidative (aerobic) decomposition by aerobic microorganism
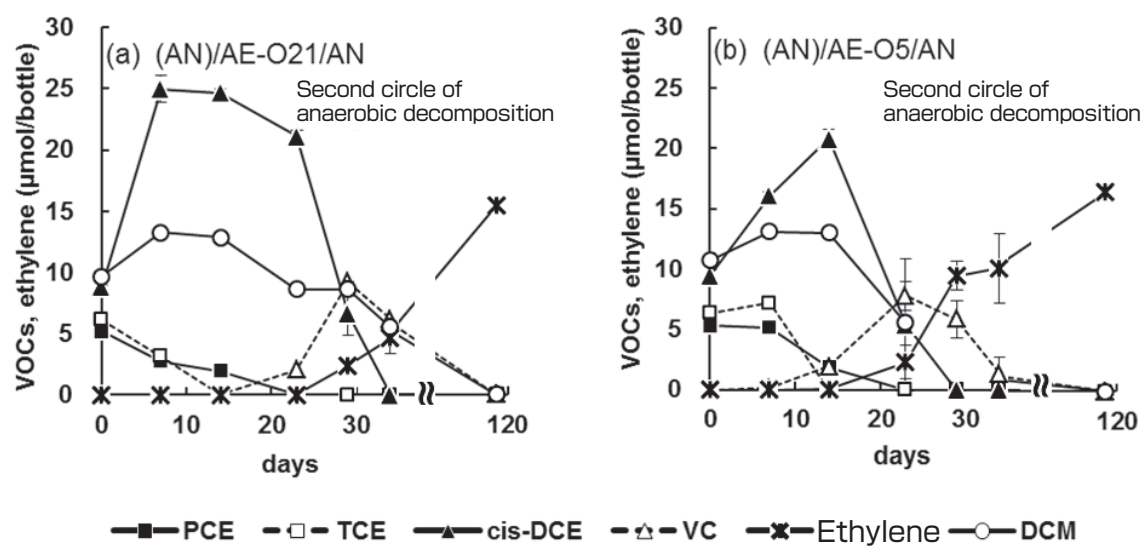

$-\approx-v c \quad-x-E$ thylene $-O-D C M$

b) Reductive (anaerobic) decomposition by anaerobic microorganism

Fig. 4 Example of complete decomposition of multiple VOCs using environmental microorganism ${ }^{[19]}$ 
Risk Research Group compiled the "Geochemical and Risk Assessment Map of Subsurface Soils" which considers the total concentration, leaching concentration of various elements including heavy metals in the subsurface soil, as well as the local industrial structure and the lifestyle of residents. The compilation of these maps was completed for the prefectures of Miyagi, Toyama, Tottori, Ibaraki, and Kochi, and the maps are available on the web (https://unit.aist. go.jp/georesenv/georisk/japanese/home/home_map.html). As an example, Fig. 5 shows the risk assessment map of Kochi Prefecture for total concentration of chromium, leaching concentration with hydrochloric acid, leaching concentration with water, and human health risks on the GoogleEarth map. It is apparent that even if the total concentration is high, the leaching concentration is not necessarily high, and even in points where leaching concentration surpassed the environmental standard, human health risks considering the local industrial structure and residents' lifestyle is extremely low. Currently, we are working on investigation and analysis for the compilation and publication of the Shikoku region, and we hope to cover the whole country in the future.

\subsection{Development of decision-making assistant tool for sustainable remediation}

Sustainable remediation is not a remediation technology itself, but is a decision making process for selecting the optimal remediation method considering comprehensively social and economic aspects as well as the environmental aspect in the countermeasures for soil and groundwater contamination. ${ }^{[8]}$ Sustainable remediation is not a remediation technology based on uniform environmental standards, but is an improved version of green remediation proposed by the Environmental Protection Agency (EPA) of USA and the American Society for Testing and Materials (ASTM) ${ }^{[21]}$ Recently, the framework for standards for sustainable remediation has been published by the International Organization for Standardization (ISO), ${ }^{[10]}$ and the author was involved in the standardization as one of the reviewers in the process. At this point, although the framework of sustainable remediation was proposed, there is no established tool for social implementation. Therefore, the author collaborated with researchers of and outside AIST to develop a tool based on a hierarchical decision-making method (Fig. 6). ${ }^{[22]}$

This is one of the decision-making processes through problem solving in which the subjective judgement and systems approach are integrated to analyze a problem. It is called the hierarchical decision process. ${ }^{[23]}$ By using this system, it becomes possible to provide an objective and neutral result, by entering and tallying relative points for subjective opinions of parties concerned in different positions, in the process of decision making by stakeholders. This enables consensus building, and decision making can be done smoothly. We are developing this tool aiming at opening it to the public.

\section{Future issues and perspective}

While the seriousness of soil contamination problem is growing in the developing countries, it is still a social issue that must be faced in developed countries such as Japan. However, in addition to the diversity of contaminants, the soil contamination problem is extremely complex due to the heterogeneity and isotropy of the geological formations as well as diversity of the soil. Therefore, in order to efficiently and effectively solve the soil contamination problem, development of knowledge and elemental technologies of a single field is insufficient. Other than development of


Fig. 5 Assessment of chromium in "Geochemical and Risk Assessment Map of Subsurface Soils" for Kochi Prefecture 
realizable technology by integration of several fields, it is necessary to integrate and synthesize flexibly. Also, it is absolutely essential to pursue more effective regulations and management.

Since large amount of expenditure is often necessary for soil contamination measures, the construction of a countermeasure and management system that considers the economic and social aspects together with environmental aspects is extremely important. Also, it is thought that the establishment of a countermeasure and management system for soil contamination that enables sustainable development and progress, as well as application of countermeasure technology based on risk assessment and selection of countermeasure technology considering the use of land are important. It is possible to integrate various elemental technologies in constructing such a system.

Although there may be parts that are insufficient or misleading due to the limitation of time and print space as well as the author's lack of knowledge or wisdom, the author hopes to contribute as much as possible not only to the soil contamination problem in Japan but also to international cooperation and collaboration for environmental problems, through deepening discussions in the future.

\section{Terminologies}

Term 1. Heavy metals: Heavy metals include metals with relatively large specific gravity, generally of over 4-5. In the laws and soil contamination field, cyanides, fluorine and its compounds, and boron and its compounds that cause health damage to humans just like the conventional heavy metals such as lead and mercury are included.

Term 2. Designated investigation organization: Organization that is set by law to conduct appropriate investigations in carrying out specific investigations based on the governing laws. In Articles 3 and 4 of the Countermeasures Act (2002), the investigation must be carried out by an entity designated by the Minister of the Environment. In this case, the entity designated by the Minister of the Environment is the designated investigation organization.

\section{References}

[1] Environmental Management Bureau, Ministry of the Environment: Heisei 27 nendo noyochi dojo osen boushiho no shiko jokyo (Enforcement status of the Soil Contamination Countermeasures Act in agricultural land for FY 2015) (2016) (in Japanese).

[2] Geo-environmental Protection Center: Waga kuni ni okeru dojo osen taisaku hiyo no suitei (Estimate of the soil contamination countermeasure cost in Japan) (2000) (in Japanese).

[3] Environmental Management Bureau, Ministry of the Environment: Heisei 28 nendo dojo osen taisaku-ho no shiko jokyo oyobi dojo osen chosa taisaku jirei to ni kansuru chosa kekka (Enforcement status of the Soil Contamination Countermeasures Act and survey results pertaining to investigations of soil contamination and countermeasure case studies for FY 2016) (2018) (in Japanese).

[4] European Environment Agency (EEA): Main contaminants at industrial and commercial sites affecting soil in Europe as \% of total, http://www.eea.europa.eu/data-and-maps/ figures/main-contaminants-at-industrial-and-commercialsitesaffecting-soil-in-europe-as-of-total/csi15_fig02.eps/ image_large, accessed 2019-01-03.

[5] Technical Committee for Soil Contamination Technology and Standards, Soil and Agrichemical Group, Central Environmental Council: Abura osen taisaku guidelineKoyurui o fukumu dojo ni kiin suru yushu yumaku mondai eno tochi shoyusha to niyoru taio no kangae-kata (Oil pollution countermeasure guideline-Views on measures by land owners etc. against oil smell and oil film originating from soil containing mineral oils, etc.) (2006) (in Japanese).

[6] M. Zhang: Dojo osen taisaku to seido no kongo (Countermeasures for soil contamination and future



Fig. 6 Example of hierarchy in decision making process for sustainable remediation ${ }^{[22]}$ 
perspective), Kankyo Kanri Taisaku To Seido No Kongo Koen Yoshishu (Proceedings of Special Seminar on Environmental Management and Future of the Problem), Organization for Research and Communication of Environmental Risk of Chemicals, 65-74 (2017) (in Japanese).

[7] T. Komai, Y. Kawabe, J. Hara, Y. Sakamoto and H. Sugita: Development of a risk assessment system for soil contamination and the application to the social systemProcesses in Synthesiology for practicing an advanced environmental risk management, Synthesiology, 1 (4), 276286 (2008) (in Japanese) [Synthesiology English edition, 1 (4), 251-262 (2009)].

[8] M. Zhang: Sustainable remediation, Journal of Japanese Geotechnical Society, 65 (1), 55-56 (2017) (in Japanese).

[9] US Sustainable Remediation Forum: Integrating sustainable principle, practice, and metrics into remediation projects, Remediation, 19 (3), 5-114 (2009).

[10] International Standard Organization: Soil qualitySustainable remediation, ISO 18504 (2017).

[11] M. Zhang: Soil Contamination Countermeasures Act (Analysis-Organics), Bunseki, 519, 100-101 (2018) (in Japanese).

[12] M. Okazaki: Introduction to the Soil Contamination Countermeasures Act, Bunseki, 517 (1), 19-20 (2018) (in Japanese).

[13] M. Kato: Soil Contamination Countermeasures Act (Analysis-Heavy Metals, etc.), Bunseki, 518, 58-59 (2018) (in Japanese).

[14] M. Hoshino, M. Zhang, M. Suzuki, K. Tsukimura, M. Ohta and T. Akita: Existence forms of lead within naturally polluted soils, Proceedings of the 19th Symposium on Soil and groundwater contamination and Remediation (2013) (in Japanese).

[15] H. Sugita, T. Oguma, M. Zhang, J. Hara and S. Takahashi: Environmental stability of spent magnesium-based and calcium-based arsenic adsorbents-Effects of soils, Journal of Japan Society of Civil Engineers G (Environment), 72 (7), III_437-III_448 (2016) (in Japanese).

[16] H. Sugita, T. Oguma, M. Zhang, J. Hara and Y. Kawabe: Effects of silicic acid on environmental stability of spent magnesium-based arsenic adsorbents, Journal of Japan Society of Civil Engineers G (Environment), 73 (7), III 407III_418 (2017) (in Japanese).

[17] H. Sugita, T. Oguma, M. Zhang, J. Hara and Y. Kawabe: Effects of silicic acid on environmental stability of spent calcium-based arsenic adsorbents, Journal of Japan Society of Civil Engineers G (Environment), 74 (7), III_493III_502(2018) (in Japanese).

[18] M. Yoshikawa, M. Zhang and K. Toyota: Enhancement and biological characteristics related to aerobic biodegradation of toluene with co-existence of benzene, Water Air Soil Pollut., 227 (9), 340 (2016).

[19] M. Yoshikawa, M. Zhang and K. Toyota: Integrated anaerobic-aerobic biodegradation of multiple contaminants including chlorinated ethylenes, benzene, toluene, and dichloromethane, Water Air Soil Pollut., 228 (1), 25 (2017).

[20] M. Yoshikawa, M. Zhang, F. Kurisu and K. Toyota: Bacterial degraders of coexisting dichloromethane, benzene, and toluene, identified by stable-isotope probing, Water Air Soil Pollut., 228 (11), 418 (2017).

[21] ASTM: Standard Guide for Greener Cleanups, E2893-13, 1-30 (2013).

[22] M. Zhang, T. Yasutaka, Y. Furukawa and M. Nakajima: Feasibility of using hierarchical decision modeling approach as a tool for decision making associated with sustainable remediation, Proceedings of the 23rd Symposium on Soil and groundwater contamination and Remediation, 811-814 (2017) (in Japanese).

[23] V. Rajput and A. C. Shukla: Decision-making using the analytic hierarchy process (AHP), International Journal of Scientific Research, 3 (6), 135-136 (2014).

\section{Author}

\section{Ming Zhang}

Obtained doctorate (Engineering) at the Graduate School of Engineering, Kyushu University in March 1996. Postdoctoral Fellow, Japan Science and Technology Corporation in October 1996. Joined the Geological Survey of Japan, Agency of Industrial Science and Technology as Chief Research Officer in July 1999. Senior Researcher, Research Center for

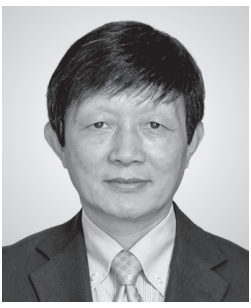
Deep Geological Environments, AIST in April 2001. Group Leader, Geo-Environmental Risk Research Group, GeoResources and Environment, AIST from April 2011. Also Professor, Collaborative Division of Graduate School of Environmental Studies, Tohoku University from April 2016. Engages in R\&D for geological disposal of radioactive wastes and environmental remediation technology for groundwater and soil.

\section{Discussions with Reviewers}

\section{Overall \\ Comment (Masahiko Makino, AIST)}

The problems of soil and groundwater contamination can have serious and major effect on human health and society, and research to seek solutions to this problem is important. In this commentary, the author provides a detailed and understandable account of the research goal, the relationship of such goal with society, the scenario, the elemental technology, and the integration of elemental technologies. Also, the author is working on the "decision making process for sustainable remediation" as a support tool for countermeasures, and future development is expected. This commentary sufficiently fulfills the review standard of Synthesiology and I recommend its publication.

Comment (Shigeki Naito, AIST)

This commentary describes the scenario for the solution of the soil and groundwater contamination problem for which long-term technology and R\&D are necessary. It explains that the decision making for contamination remediation is important to tackle the challenging topic that contributes to achieve the 17 "sustainable development goals (SDGs)" through the integration of wideranging research subjects, elemental technology development, and environmental, economic and social aspects. I think it is suitable for publication in Synthesiology.

\section{Introduction \\ Question \& Comment (Shigeki Naito)}

You mention "since the Industrial Revolution in the latter 18th century in Japan," but mining was being done since the Sengoku (Warring States) period, and the development of heavy industry occurred in the Meiji period. Therefore, shouldn't you say, "since the establishment of government-managed Yawata Steel Works in 
the late 19th century to beginning of the 20th century"? Answer (Ming Zhang)

As you indicated, the history of mining in Japan is old, and the development of heavy industry starts in the latter 19th century. "Ashio Copper Mine Pollution" was the first recognized pollution in Japan, and is considered the origin of pollution problems in Japan. To avoid misunderstanding, I revised the text to "accompanying the development of heavy industry from latter half of the 19th century." Although mining had been done before that, I don't think it was a major activity. I also added that the "Ashio Copper Mine Pollution" was the "origin of pollution problems in Japan."

\section{Synthesiological significance of the soil and groundwater contamination \\ Question \& Comment (Shigeki Naito)}

What are the technologies of the "technologies for risk communication, etc. based on risk assessment"?

\section{Answer (Ming Zhang)}

While there are uncertainties in risk assessment, basically it can be calculated and assessed scientifically using the exposure amount and degree of toxicity of the contaminant, and risk communication is a socio-psychological approach. In this commentary, we use the phrase "technology of risk communication, etc. based on risk assessment" to express the communication technique of how to deliver scientific and objective findings so the audience can understand, to obtain acceptance or understanding about the risks to develop consensus.

\section{Technological development for investigation and assessment}

Question \& Comment (Shigeki Naito)

I think you should briefly describe the analysis method for the "clarification of present form of lead-containing minerals using sedimentation classification and X-ray diffraction analysis, and the quantitative analysis." You explain that in "the two samples collected at a certain site, one sample showed a positive correlation between lead concentration and particle size, and a good correlation with galena content. In the other sample, there was a negative correlation between lead concentration and particle size, and a positive correlation with alunite content." The reader may suspect that this is a method that is meaningful as a quantitative analysis. I think you should add some more explanation to the conclusion, not just the results, or else it will be confusing.

\section{Answer (Ming Zhang)}

As you indicated, I added an outline of the analysis method. I also added some text about the significance of the results.

\section{Technological development on remediation and countermeasure \\ Question \& Comment 1 (Masahiko Makino)}

For the graph for "Fig. 4(b) Reduction decomposition by anaerobic microorganism," I find it disturbing that ethylene is increasing as the days go by. You write in the commentary that decomposition was confirmed, so can you provide understandable explanation for this graph? Also, you have (a) and (b) in the figure, but provide no explanation.

Answer 1 (Ming Zhang)

The reductive decomposition of $\mathrm{PCE}$ by anerobic microorganism is also called the successive dechlorination reaction, and the breakdown occurs by route $\mathrm{PCE} \rightarrow \mathrm{TCE} \rightarrow \mathrm{DCE}$ $\rightarrow \mathrm{VC} \rightarrow \mathrm{ETH}$ (ethylene). Since ETH is harmless unlike the PCE, TCE, DCE, and VC that are toxic, the breakdown all the way to ETH is called the complete decomposition. To make this point more understandable, I made some revisions to the commentary. Also, there is a possibility that other than cis-DCE, TCE may be decomposed to trans-DCE or 1,1-DCE depending on the type of microorganism, but in the experiment result by the author et $a l$. as well as most reports from Japan and around the world, the decomposition occurs via cis-DCE route.

The (a) and (b) in the figure correspond to different testing conditions (headspace oxygen concentration set at the initial stage of the oxidative decomposition test), and I added this point in the commentary. Headspace is the space in test bottle that is not filled by liquid or solid soil particles. Since this is a rather complex and specialized test, I avoided detailed description in this commentary, and I hope the readers who are interested will refer to the original open access paper.

\section{Question \& Comment 2 (Shigeki Naito)}

You have a summary of papers in Reference [15]-[20] as the author's research. How about providing some explanation about what kind of efforts you made toward realization as well as conditions at which you replicated the combined pollution seen at an actual contaminated site? Also, Fig. 4 is too small. I think you should make it bigger if you wish to show something.

\section{Answer 2 (Ming Zhang)}

As you indicated, for immobilization, I added a text about the types of soils investigated. For the combined pollution by VOCs, I added the reason on why we set the particular conditions.

The figures were enlarged so the words can be read. Based also on comments from the other reviewer, I also added a text about testing conditions. 